\title{
¿Cómo promover la Ciudadanía Digital?
}

\section{¿How to promote digital citizenship?}

\author{
ALMEIDA-AGUILAR, M. Alejandrina*†, RAMOS-MÉNDEZ, Eric, JÉRONIMO-YEDRA, Rubén y \\ GÓMEZ-RAMOS, José Luis
}

Universidad Juárez Autónoma de Tabasco, División Académica de Informática y Sistemas

ID $1^{\mathrm{er}}$ Autor: M. Alejandrina, Almeida-Aguilar / ORC ID: 0000-0003-1778-8802, Researcher ID Thomson: Q-2411-2018, CVU CONACYT ID: 669831

ID $1^{\text {er }}$ Coautor: Eric, Ramos-Méndez / ORC ID: 0000-0002-5634-3286, Researcher ID Thomson: Q-1415-2018, CVU CONACYT ID: 87695

ID $2^{\text {do }}$ Coautor: Rubén, Jéronimo-Yedra / ORC ID: 0000-0003-1617-7444, Researcher ID Thomson: Q-1383-2018, CVU CONACYT ID: 669977

ID $3^{\text {er }}$ Coautor: José Luis, Gómez-Ramos / ORC ID: 0000-0003-3250-2489, Researcher ID Thomson: Q-1736-2018, CVU CONACYT ID: 670757

DOI: 10.35429/JITC.2019.9.3.13.23

Recibido 06 de Junio, 2019; Aceptado 25 de Septiembre, 2019

\begin{abstract}
Resumen
Son diversos los intentos que se han hecho en México en los últimos años y a través de los diferentes sexenios de Gobierno, para insertar las Tecnologías de la Información y comunicación (TIC) en el proceso de enseñanza y aprendizaje en los niveles de educación básica. Lo anterior, se intentó por medio de la creación de múltiples programas del Gobierno Federal para dicho fin. Uno de esos programas establece las competencias digitales y dentro de estas se puede ubicar la competencia de Ciudadanía Digital. El presente trabajo muestra un pequeño bosquejo de la competencia de ciudadanía digital en estudiantes de nuevo ingreso de Instituciones Educativas del Estado de Tabasco. La ciudadanía digital no tiene un solo enfoque, existen múltiples aristas de las cuales se le puede abordar. Finalmente, se exponen algunas propuestas de diversas acciones, a través de las cuáles se puede lograr la adquisición de ésta competencia digital. Los docentes, como agentes activos en el proceso de la enseñanza y el aprendizaje, pueden ser actores importantes a través del fomento de las actividades y prácticas propuestas.
\end{abstract}

Competencias digitales, Ciudadanía digital, Sexting

\begin{abstract}
There are several attempts that have been made in Mexico in recent years and through the different six-year periods of Government, to insert Information and Communication Technologies (ICT) in the teaching and learning process at the levels of basic education. The foregoing was attempted through the creation of multiple Federal Government programs for that purpose. One of these programs establishes digital competencies and within these can be located the competence of Digital Citizenship. The present work shows a small outline of the competition of digital citizenship in new students of Educational Institutions of the State of Tabasco. Digital citizenship does not have a single focus, there are multiple edges that can be addressed. Finally, some proposals for various actions are exposed, through which the acquisition of this digital competence can be achieved. Teachers, as active agents in the teaching and learning process, can be important actors through the promotion of the proposed activities and practices.
\end{abstract}

Digital competences, Digital citizenship, Sexting

Citación: ALMEIDA-AGUILAR, M. Alejandrina, RAMOS-MÉNDEZ, Eric, JÉRONIMO-YEDRA, Rubén y GÓMEZRAMOS, José Luis. ¿Cómo promover la Ciudadanía Digital?. Revista de Tecnologías de la Información y Comunicaciones. 2019. 3-9: 13-23

\footnotetext{
* Correspondencia del Autor (Correo electrónico: alejandrina.almeida@ gmail.com)

$\dagger$ Investigador contribuyendo como primer autor.
} 


\section{Introducción}

A través de diferentes sexenios en México se ha tratado de integrar el manejo de las TIC a la enseñanza, impulsando con esto la adquisición de las competencias digitales en los estudiantes. En el año 2003 fue creado el programa de Enciclomedia, esto fue durante el período del gobierno de Vicente Fox Quesada en el sexenio 2000-2006.

De acuerdo a la Facultad Latinoamericana de Ciencias Sociales (2008), el objetivo general era incorporar Enciclomedia como una herramienta para mejorar la educación en escuelas públicas buscando impactar el aprendizaje a través de la estimulación de nuevas práctica pedagógicas, fortaleciendo con esto los procesos de enseñanza aprendizaje con el uso de las TIC.

Dentro de las problemáticas encontradas en este programa, la Facultad Latinoamericana de Ciencias Sociales (2008), indica que:

No se tenían diagnósticos actualizados de las problemáticas atendidas.

El fin y el propósito del programa no estaban claramente definidos.

Afirma que no es posible atribuir únicamente al rezago tecnológico las causas de los deficientes problemas de aprendizaje.

El aspecto de mayor cuidado que encontraron los evaluadores, es la ausencia del factor pedagógico de manera adecuada en el diseño del programa.

En el sexenio de Felipe Calderón Hinojosa 2007-2012, se creó el Programa Habilidades Digitales para Todos (PHDT) y de acuerdo a la Secretaría de Educación Pública (2008), el objetivo del programa fue brindar elementos para el manejo de la información para apoyar el aprendizaje de los estudiantes ampliando así sus competencias para la vida y desarrollando las habilidades que demanda la sociedad del conocimiento.

En el informe de evaluación de desempeño efectuado por el Consejo Nacional de Evaluación de la Política de Desarrollo Social (2010-2011), (CONEVAL); indica que:
No cuenta con evaluaciones de impacto debido a que aún se estaban ajustando aspectos relacionados con su gestión y operación.

De igual forma, hizo la observación de no descuidar la capacitación ya que sin este elemento el programa dejaría de obtener efectos positivos. Finalmente recomendaba no descuidar la la articulación de las TIC en la enseñanza.

De acuerdo a la Secretaría de Educación Pública (2011), en México, el Acuerdo 592 por el que se estableció la Articulación de la Educación Básica, estableció Estándares de Habilidades Digitales para estudiantes y docentes, el programa HDT fue abrogado en virtud de que se consideró que su objetivo se había cumplido Diario Oficial de la Federación (2014).

Sin embargo, este acuerdo fue el que estableció las habilidades digitales que deberían tener los docentes y estudiantes:

Creatividad e innovación.- Implica que alumnos y maestros desarrollen materiales como fotos, videos, presentaciones animadas entre otras, donde las TIC se usen creativamente y apoyen la construcción de conocimientos escolares.

Comunicación y colaboración.- Hace referencia a la utilización de medios y entornos digitales para alumnos y maestros comuniquen sus ideas, interactúen y aprendan a trabajar colaborativamente con otros.

Investigación y manejo de la información.- Hace referencia a la importancia de aprender a usar las TIC para recabar, seleccionar, analizar, evaluar y utilizar información, procesar datos y comunicar resultados.

Pensamiento crítico, solución de problemas y toma de decisiones.- Los alumnos y maestros deben saber planear, organizar y llevar a cabo investigaciones, administrar proyectos, resolver problemas y tomar decisiones con base en información veraz y utilizando herramientas digitales.

Ciudadanía digital.- Hace referencia a la utilización de las TIC con ética, legalidad, de forma segura y responsable dentro de un espacio público. 
Funcionamiento y conceptos de las TIC.Implica la comprensión sobre el funcionamiento de las TIC, con el fin de seleccionar las más adecuadas de acuerdo a sus necesidades y las utilicen productivamente para transferir los conocimientos adquiridos. En el gobierno de Enrique Peña Nieto, dentro del Plan Nacional de Desarollo 2013-2018, surge La Estrategia Digital Nacional cuyo próposito es lograr un México digital en la adopción y uso de las TIC (Peña, 2013).

\section{Problemática}

Previo a este trabajo, se determinó el nivel de las competencias digitales de los alumnos de nuevo ingreso de carreras relacionadas con las TIC de las instituciones más representativas de Villahermosa, Tabasco: Universidad Juárez Autónoma de Tabasco, Instituto Tecnológico de Villahermosa y la Universidad del Valle de México campus Villahermosa. Para esto se utilizó como instrumento para la recolección de datos un cuestionario con preguntas cerradas utilizando una escala tipo Likert.

En los resultados, una de las competencias con el nivel más bajo fue el de ciudadanía digital. Uno de los principales problemas que existe en el alumnado, es el mal uso que se hace de las TIC.

Invariablemente uno de los aspectos donde salen muy mal evaluados los estudiantes es en el respeto a los derechos de autor, existe desconocimiento de los diferentes tipos de licencias que hay, desconocen el respeto que deben de observar en la "convivencia" dentro de espacios públicos digitales, las reglas de netiqueta, el cuidado que deben de tener con el manejo de su información personal e imagen en las redes sociales, entre otros.

De acuerdo a estos resultados y tomando en cuenta que la tecnología permite una mayor movilización ciudadana en defensa de causas sociales, es imprescindible la formación de los principales actores para lograr ua ciudadanía digital integrada y responsable (García, Fernández \& Del hoyo, 2017).

\section{Metodología}

El enfoque de investigación utilizado en este trabajo fue el cualitativo de tipo documental con un alcance exploratorio.
A partir de la observación de hechos particulares, se realizó la búsqueda, selección y análisis de documentos relacionados con esta temática, los cuales fueron usados como herramientas de recolección de datos.

\section{Objetivo General}

Diseñar una propuesta para que a partir del conocimiento de las diversas aristas que tiene la Ciudadanía Digital, se promueva su práctica como una parte inherente a las actividades académicas que impliquen el uso de las TIC.

\section{Ciudadanía Digital}

Lizcano (2012, p.8), cita a Borja(2002), quien define el termino ciudadanía como:

"la calidad que adquiere el que teniendo una nacionalidad y habiendo cumplido las condiciones legales requeridas asume el ejercicio de los derechos politicos que le

habilitan para tomar parte activa en la vida pública del Estado y se somete a los deberes que le impone sus calidad."

El concepto de ciudadanía esta definido en nuestra sociedad, así como también sus derechos y obligaciones, los cuales deben ser aplicados a todo los ciudadanos por igual. Estos derechos y obligaciones se encuentran definidos dentro de la Constitución Política de los Estados Unidos Mexicanos (1917).

De acuerdo a Marshall, citado por Olvera (2008, p. 20), los derechos de ciudadanía, se desarrollan en tres dimensiones: la civil, la política y la social.

Orozco y Silva (2002), conceptualizan esas tres dimensiones de la siguiente forma:

Los derechos civiles son aquellos que protejen la vida, la igualdad, la libertad, la seguridad y la integridad fisica del individuo así como de sus propiedades y éstos estan contenidos en básicamente en los primeros 29 artículos de la Constitución Política de los Estados Unidos Mexicanos (1917).

La prerrogativa del ciudadano, que se conoce como derecho político, básicamente en el artículo 35 de la misma Constitución. 
Y los derechos sociales son los que aseguran el bienestar social, económico y cultural de ciertos grupos sociales y se encuentran diseminados en diversos artículos como el 3ro, 4to, 27 y 136.

Ahora bien, a diferencia del término ciudadano, el de ciudadano digital aún no esta bien definido ni acotado.

En la vida diaria existen diversas normas de respeto y tolerancia para la sana convivencia, huelga decir que esas normas de respeto y tolerancia así como ciertos valores de la vida cotideana de las personas, deberían trascender a la vida online. Sin embargo, esas normas no siempre son respetadas y esto se potencializa aún más en Internet, ya que las personas creen que existe el cobijo del anonimato, sin embargo con el uso de las redes sociales, eso ya no es del todo cierto.

Retomando el concepto de Ciudadanía digital dado con antelación, éste hace referencia a la utilización de las TIC con ética, legalidad, de forma segura y responsable.

Se puede afirmar que existen diversas perspectivas o aristas desde las cuales se puede ver la ciudadanía digital, en este caso nos interesa ver algunas de ellas:
a. Ética
b. Legalidad
c. Política y sociedad
d. Uso de las Tic de forma segura y responsable

a) Ética.- de acuerdo a la Academia Real Española, es el "conjunto de normas morales que rigen la conducta de la persona en cualquier ámbito de la vida", DRAE(2017). La ética es un campo que pertenece al campo de la filosofía, cuyo objeto de estudio es la moral, vista ésta como el conjunto de valores, actitudes, normas y costumbres cuyo propósito es regir la conducta del hombre (De Zan 2004, p.19).

El Centro de Estudios LACE(s.f), hace referencia a los distintos conjuntos de normas que buscan regular el comportamiento del individuo, de los cuales se hará referencia a los siguientes:
Normas Morales, las cuales buscan el bien individual así como el común, ejemplos de éstas puede ser la solidaridad, el respeto, la responsabilidad, honestidad, no hablar sobre acciones de otra personas de las que uno no esta autorizado a decir, la tolerancia, entre otros.

Normas Sociales, que buscan la sana convivencia entre los individuos. Dentro de estos estan el saludo, pedir permiso, disculparse, evitar el lenguaje obceno, no gritar, respeto por las opiniones que son diferentes a las propias.

En los medios electrónicos algo similar sería el termino que se define como Netiqueta, y son las normas de conducta o reglas que regulan el comportamiento del usuario en los medios electrónicos.

Así como en la vida real existe reglas de urbanismo para la sana convivencia de los ciudadanos, del mismo modo se debe de tener respeto por las personas que "viven" en la red. Es importante conocer esas reglas y tratar de usarlas, ya que cada vez el ámbito en el que convivimos es más digital que presencial.

b) Legalidad.- De acuerdo con el DRAE(2017), la legalidad es lo que tiene "cualidad de legal". Corresponde en este punto discernir sobre la legalidad de los derechos de autor, la propiedad intelectual y las TIC (Tecnologías de la Información y Comunicación).

¿Qué es la propiedad intelectual?

Es el conjunto de normas que regulan la creación del intelecto humano, entonces "es el derecho de pertenencia de una creación" (García 2013, p.21). Estas creaciones, pueden ser:

Propiedad industrial, cuando se trata de un diseño industrial, la creación de la marca de un producto, una invención, entre otros.

Derechos de autor, los cuales hacen referencia a todo lo concerniente a obras de la literatura como libros, música, fotografía, pinturas, esculturas, películas, programas informáticos y bases de datos electrónicas.

¿Quién se encarga de la protección de la propiedad intelectual en Internet $y$ especificamente de los derechos de autor? 
Existe el Convenio de Berna (1886) para la protección de la obras literarias y artisticas, de la administración de este tratado se encarga la Organización Mundial de la Propiedad Intelectual (OMPI) (OMPI 2016, p.3).

En cuestión de derechos de autor, en México existe la Ley Federal de Derechos de Autor (LFDA) y la Ley de Propiedad Industrial y corresponde al Instituto Mexicano de la Propiedad Industrial (IMPI) proteger esos derechos ya que la violación de éstos es considerado como un delito grave (Garzón 2016).

¿Qué importancia tiene la propiedad intelectual? De acuerdo a $\mathrm{IMCO}$ (s. f., p. 15), indica que de acuerdo a Falvey et al (2004), existe una relación entre el respeto a la propiedad intelectual y el crecimiento del PIB (Producto Interno Bruto), debido a que los paises de ingreso alto, dependen de sus innovaciones para la mejora de su economia, mientras los paises de ingreso medio se dedican a copia sin innovar, lo cual tiene como resultado que éstos últimos solo sean ensambladores y y no produzcan bienes o productos de alto valor comercial.

Es de suma importancia incentivar y fortalecer el respeto que se debe de observar al trabajo de otras personas -derechos de autor-, así como también a compartir el conocimiento.

Una alternativa sencilla son las licencias Creative Commons (ver figura 1), las cuales permiten de una manera sencilla gestionar la licencia para alguna obra y esta a disposición del público en general.

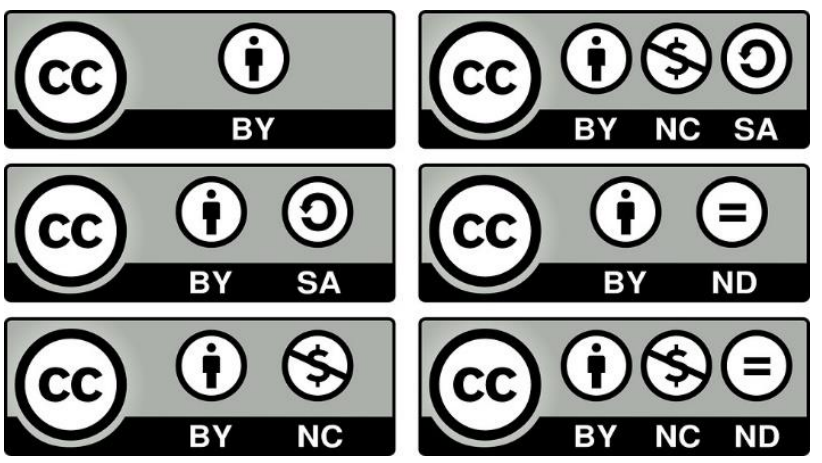

Figura 1 Los tipos de Licencia de Creative Commons Fuente: www.pixabay.com/es

c) Política y sociedad. Las redes sociales en los últimos años han jugado un papel determinante dentro de la vida política.
Un ejemplo de ello es la formación de la organización wikipolítica, en el año 2014, formado por académicos y jóvenes universitarios. Inició en el estado de Jalisco, sin embargo actualmente se encuentra en otros estados del país, buscando principalmente promover la participación ciudadana a través de los medios digitales. Esto muestra el gran potencial que poseen los medios sociales para orientar e incentivar iniciativas ciudadanas y lograr el empoderamiento colectivo (Gravante, Sierra \& Leetoy 2018).

Ese empoderamiento no debe ser exclusivo del ámbito político, es importante también la participación ciudadana en cuestiones ecológicas como lo son las consecuencias del cambio climático, para ello es importante contar con habilidades digitales que permitan establecer esos vinculos con la sociedad (Rodrigo-Cano, Picó \& Dimuro, 2019).

Lo anterior concuerda con lo escrito por Lugo \& Ithurburu (2019), quienes indican que la alfabetización digital se puede ver como un nuevo campo de conocimientos, de modo tal que su adquisición permite la inclusión en la vida social.

Sin embargo, es importante aclarar en este punto que la capacitación debe ser de manera crítica, ya que como afirma Mesa (2019a), este contexto no es neutro y debe de haber límites en el sentido de que no deben de usar los medios digitales para transmitir discursos de odio, descalificación y confrontación.

En este punto, cabe reflexionar sobre la gran brecha digital que existe entre la población, de igual forma, es importante aclarar que para que exista ese empoderamiento ciudadano es indispensable la creación de espacios públicos digitales y el acceso a ellos, sí como la formación ética de la ciudadanía.

d) Uso de las TIC de forma segura y responsable. Dentro de los problemas por el uso inadecuado de las TIC, se tienen diversos elementos Fig. 2: 


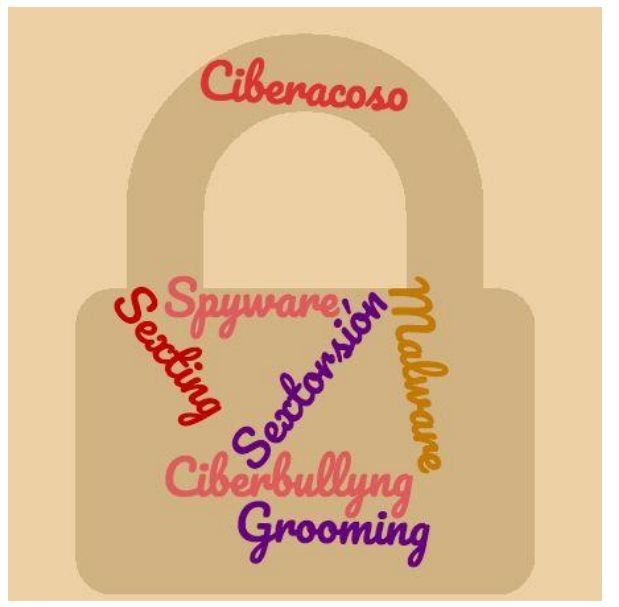

Figura 2 Problemas por el uso inadecuado de las TIC Fuente: Elaboración Propia

SEXTING.- Es un concepto que ha irrumpido en escena, en relación con los menores de edad y el uso seguro y responsable de las TIC. Esta palabra trata de reflejar la fusión entre sexo y texting, que son mensajes vía SMS desde teléfonos móviles. Este término se utilizó por primera vez por Yvonne Roberts en la Revista Sunday Telegraph en el 2005 (José, 2010), y como lo indica el Instituto Nacional de las Tecnologías de la Comunicación (INTECO), aunque originalmente se limitaba a textos(SMS), el vertiginoso avance tecnológico ha influido demasiado para cambiar ese concepto inicial (San-José, et al., 2011 p.6).

De acuerdo a Universia(2012), en el 2007 surgen los smartphone con la caracteristica importante de tener acceso a internet y por ende a las redes sociales, por otra parte ya todos los nuevos dispositivos (teléfonos, tabletas, computadoras) traen integrada una camara, lo cual cambia un el concepto inicial de sexting.

El inteco lo define como al envío de fotografias y videos con contenido de cierto nivel sexual, tomados o grabados principalmente por los protagonistas y se hace generalmente a través del teléfono móvil, (San-José, et al., 2011 p.6).

Mendo (2016), presenta una clasificacion del texting, refiriendose al texting primario como aquel que se da cuando de manera voluntaria una persona que se encuentra en una relación privada con otra, protagoniza imágenes con contenido sexual y se las envía a su pareja; el texting secundario lo define como la difusión de las imágenes entre terceras personas a través de las TIC, sin el concentimiento de los protagonistas.
El sexting no es un suceso que se de solo entre los menores de edad, se da también en personas adultas, sin embargo existe énfasis en los menores de edad por que son más vulnerables. Desafortunadamente la evolución tecnológica facilita que en un impulso y sin reflexionar, se envíe y una vez difundido ....... No hay vuelta atrás.

El hecho de que el teléfono esté tan a mano, facilita la toma de una selfie aún en momentos íntimos y que se comparta con mucha facilidad en redes sociales.

Desafortunadamente según Jiménez (2018), cada vez va disminuyendo la edad de los niños que practican sexting, el Consejo Ciudadano de la Ciudad de México detectó un "pack" de fotos eróticas en niños de primaria, dicha práctica se ha extendido en niños de 5to. y 6to. grado de primaria. En el ciclo escolar 20172018, el concejo ciudadano visitó 21 primarias y en la mitad los estudiantes mostraron inquietud e interes por esta actividad, reconociendo que ya la habian prácticado.

\section{¿Qué riesgos conlleva el sexting?}

Ciberacoso.- El ciberacoso es un agresión que se realiza sobre alguna persona, utilizando dispositivos digitales y puede dar a través de mensajes, redes sociales, correos electrónicos para difundir imágenes o hechos, ya sean verdaderos o falsos; los cuales tienen el único propósito de ofender, humillar o causar vergüenza (Gobierno Federal de los Estados Unidos s.f.).

Es importante aclarar que este es un suceso donde se encuentran involucrados adultos.

Ciberbullyng.- Aunque muchos traten el ciberacoso y el ciberbullyng como lo mismo, existe una diferencia: el ciberbullyng se da entre niños y/o adolescentes, donde de igual forma, utilizando dispositivos digitales como computadoras, tabletas o teléfonos celulares; son victimas de burlas, humillaciones $\mathrm{o}$ discriminación por cuestiones como su aspecto físico, color de piel, forma de vestir, estatus ecónomico, entre otras aspectos (UNOTV, 2017 y Lider Noticias, 2017). 
La ONG internacional Bullyng Sin fronteras, realizó un estudio sobre el bullyng entre abril de 2017 y abril de 2018, tristemente entre los resultados publicados, México se ubica en el primer lugar a nivel mundial en casos de bullyng y acoso escolar. Dentro de las problemáticas detectadas, encontraron la ausencia de denuncias tanto a los maestros o autoridades escolares como ante la ley. Por esta situación, se reporta una ausencia a nivel nacional de 3 millones de niños al mes (ONG Internacional Bullying sin fronteras, 2018).

Sextorsión.- Extorsión o chantaje a una persona por imágenes suyas, el chantaje no necesariamente es de carácter económico, puede ser también obligando a la persona a tener relaciones sexuales, desafortunadamente existen sitios que se prestan a esto y publican fotos, videos, el nombre real de las personas y requeríendo un pago para eliminar las imágenes (Internet Reputation s.f.).

Grooming.-El problema con el grooming, es que el acosador es un adulto, quien ha desarrollado habilidades para que a través de perfiles falsos se gane la confianza del menor a través de internet, y generalmente es para obtener concesiones de índole sexual o para realizar trata de personas.

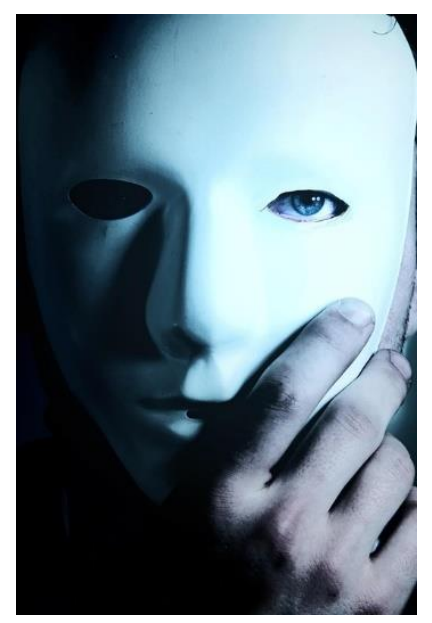

Figura 3 Grooming

Fuente: Leandro De Carvalho (Pixabay)

\section{Software malicioso}

Malware.- Hace referencia al software malicioso como virus, troyanos, entre otros. Hoy en día, los malware más avanzados están formados por diferentes componentes, cada uno de ellos con una tarea diferente. Estos programas permiten al cibercriminal realizar múltiples acciones en el equipo infectado.
Uno ejemplo de esto, es el keylogger, una herramienta específica diseñada para registrar las pulsaciones en el teclado de un equipo. Gracias a este programa, los delincuentes pueden robar un gran volumen de información confidencial sin que la víctima se percate de ello. De acuerdo a Kaspersky, un keylogger es un software o hardware que puede interceptar y guardar las pulsaciones realizadas en el teclado de un equipo que haya sido infectado, intercepta y registra información sin que el usuario lo note. A través de ellos se pueden conocer información confidencial como contraseñas, números de tarjetas de crédito o información financiera, (Kaspersky, s.f.).

Otro software que se puede instalar en una computadora o teléfono móvil es el spyware, el cual permite tener acceso a la cámara del dispositivo y tener control sobre ella, este software puede afectar también teléfonos móviles, un ejemplo de ello es Pegasus que permitía espiar iPhones. Android en este caso no es la excepción, Chrysaor fue creado para tener como objetivo los dispositivos Android, teniendo acceso a Whatsapp, Facebook, Twitter, Skipe, Gmail, a la cámara y micrófono del dispositivo y al mismo tiempo actuaba como keylogger, registrando pulsaciones del teclado, (pandasecurity, 2017).

\section{Propuesta}

A continuación se presentan propuestas de diversas acciones que se pueden realizar como docentes para promover la ciudadanía digital.

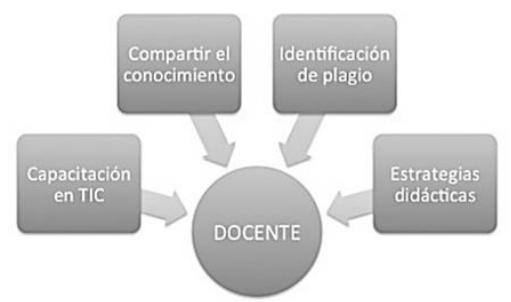

Figura 4 Acciones para promover la ciudadanía digial Fuente: Elaboración Propia

a) Es indispensable saber detectar $y$ distinguir cada uno de los conceptos tratados, tener material didáctico de acuerdo a sus edades para informar a los alumnos en qué consiste cada una de esas prácticas. 
En España existe el Programa de Pantallas Amigas, que es una iniciativa para el uso seguro de Internet y las TIC en la infancia y adolescencia así como también para una ciudadanía digital responsable, esta página trata temáticas relacionadas con el sexting, grooming, etc., y han creado diversos videos y documentos relacionados con estos conceptos, que los profesores podrían socializar con alumnos y padres de familia.

b) Las siguientes sugerencias, son actividades que pueden ayudar a fortalecer el respeto a los derechos de autor:

Como docentes, es indispensable capacitarse en el este ámbito para poder guíar a los alumnos.

Es importante indicar a los alumnos que antes de tomar algo de la la red, se debe verificar si no se estan infringiendo los derechos de autor, si se toma algo que este permitido, respetar el tipo de licencia, por ejemplo si requiere reconocimiento, hacer la cita respectiva.

Ser consciente que como docente, es importante capacitarse en el manejo de TIC y manejar herramientas para detección de plagio. No solo en lo escrito puede existir el plagio, también en las imágenes que se toman de la red, por tal motivo se debe orientar a los alumnos en el manejo del buscador y explicarles como donde y cómo buscar imágenes que pueden ser reutilizadas $\mathrm{y} / \mathrm{o}$ modificadas sin infringir los derechos de autor.

Explicarles el funcionamiento de los diferentes tipos de licencias, de modo tal que puedan puedan usarlas con certeza.

Existen sitios donde se pueden descargas imágenes gratuitas, asegurarse que los conocen. También se hace referencia en este punto, a compartir el conocimiento, esto es importante ya que ayuda a socializar el conocimiento y es una oportunidad para todos los miembros de aportar ideas al proyecto. Algo que se debe incentivar y cuidar que se cumpla en este punto, es que esta actividad no debe de ser un resumen de la información que obtuvieron, deben de transformar la información obtenida de modo tal que para ellos sea una pequeña práctica para la innovación.
¿Qué actividades se pueden fomentar en el aula para poder lograrlo?

La creación de videos educativos utilizando para ello software libre, esto último para no infringir ninguna ley y por su gratuidad.

Compartir los videos en una red como puede ser YouTube.

Creación de un blog de igual forma con software libre como puede ser Word Press o en Blogger, donde compartan sus conocimientos y hasta los mismos videos que crearon.

Finalmente, cuando un alumno entrega alguna tarea o trabajo, es responsabilidad del docente verificar que no exista plagio en los documentos e imágenes utilizadas por el alumno. Existen diversos tipos de software para auxiliarlos en esa tarea.

En este punto es muy probable que estas actividades se contemplen como trabajo para llevar a casa para el docente, sin embargo se puede realizar en este punto la evaluación por pares, la cual puede ser intragrupo o intergrupo. Para que esta actividad se pueda dar de manera efectiva, es importante tener una planeación:

1. 1.- Elaboración de una rubrica de parte del profesor donde al elaborarla tenga cuidado en plasmar todos los criterios a evaluar

2. 2.- Socializar la rubrica entre los alumnos, de forma tal que tengan claro cuales seran los criterios que deben evaluar.

3. 3.- Entrega de rubrica e informe. Una vez realizada la evaluación por los pares, éstos deberan entregar la rubrica de evaluación correspondiente así como un pequeño informe donde justifique $\mathrm{o}$ explique de manera breve la puntuación asignada.

c) Identificar plataformas de Recursos abiertos masivos y gratuitos de la Secretaría de Educación Pública donde existen cursos en línea para la formación del docente. 
d) Nada impide que las redes sociales que comunmente se utilizan para la comunicación y el entretenimiento, se puedan utilizar dentro del ámbito educativo como plataformas para compartir el conocimiento. Una estrategia didáctica que puede tener un profesor, es la creación de un grupo de whatsapp en alguna asignatura, lo cual permite entre otras cosas:

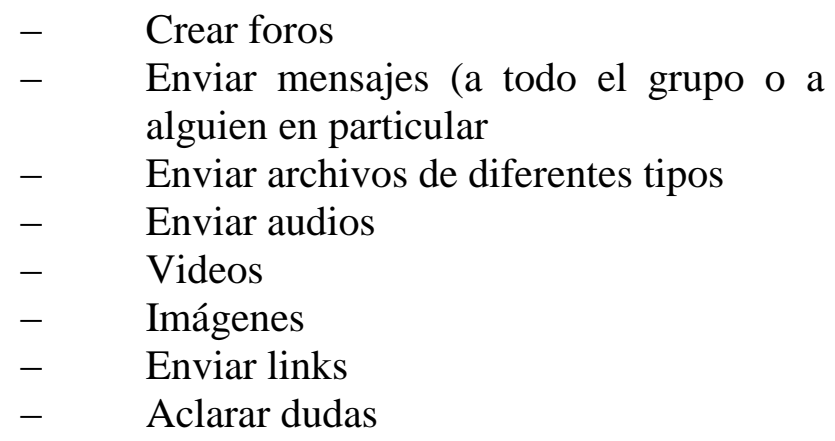

De igual forma puede ser la creación de un grupo cerrado de facebook o enviarles información por correo electrónico.

Como se mencionó anteriormente, al coexistir varias personas en un grupo, se deben de marcar reglas.

Y como afirma Mesa (2019b) "desde el punto de vista de los valores se trata de impulsar el sentido de la ciudadanía global, la igualdad de derechos, el respeto, la tolerancia y la apreciación de la diversidad".

Existen las reglas de netiqueta para el buen uso y convivencia en las redes sociales.

No es nuevo que ya se ha analizado el uso de las redes sociales en la educación como herramienta de enseñanza y aprendizaje. Para darles un uso correcto, es importante que el profesor este familiarizado con esas reglas y las comparta con sus alumnos.

e) Existen asignaturas en algunas instituciones relacionadas con la ética, es importante que dentro de ellas se vean las reglas de netiqueta mencionadas anteriormente, porque la red también es un lugar donde todos tenemos que convivir.

\section{Conclusiones}

Dentro de la asignatura de informática educativa, se trabajó esta propuesta, desde el rol de docente. Los alumnos crearon su propios blogs de manera individual, compartiendo desde ahí sus trabajos y los videos creados por ellos mismos. Para esto, se realizó previamente una rubrica la cual les fue entregada y explicada. Finalmente se realizó la evaluación por pares verificando las licencias de las imágenes utilizadas en el blog y los trabajos así como también el respeto a los derechos de autor en la música utilizada en los videos e información escrita en los blogs. Fue una actividad que les hizo poner en práctica su creatividad así como sus conocimientos en dos diferentes momentos: en el momento de desarrollar su blog y en el momento de la evaluación por pares.

De esta iniciativa, se lograron trabajos muy creativos, de los cuales actualmente se esta iniciando el proceso del registro de propiedad intelectual.

Como maestros, padres de familia y sociedad, es importante saber en que consiste cada una de estas prácticas, como se dan, a partir de que edad se están realizando y sobre todo estar informado y saber que se puede hacer desde la perspectiva del papel que a cada cual le corresponda ejecutar.

Sin embargo hace falta fomentar la cultura de la denuncia para que se den los cambios en las leyes y se atiendan los vacíos que existen. La gran tarea pendiente que existe y no solo en nuestro pais, es legislar el mundo digital.

\section{Referencias}

Centro de Estudios LACE(s.f.). Ética. Antología. Departamento de Desarrollo Academico. Recuperado de: https://es.calameo.com/books/0028159571c3f5f $488 \mathrm{~d} 4 \mathrm{c}$

Consejo Nacional de Evaluación de la Política de Desarrollo Social (2010-2011). Informe de Evaluación Especifica de Desempeño 20102011 del Programa de Habilidades Digitales para Todos. México. Consultado el 13 de agosto de 2017 en: https://www.coneval.org.mx/rw/resource/conev al/EVALUACIONES/EVALUACIONES_PRO GRAMAS_POLÍTICAS_DS/EED_20102011/SEP/habilidades_digitales/completo.pdf

ALMEIDA-AGUILAR, M. Alejandrina, RAMOS-MÉNDEZ, Eric, JÉRONIMO-YEDRA, Rubén y GÓMEZ-RAMOS, José Luis. ¿Cómo promover la Ciudadanía Digital? Revista de Tecnologías de la Información y Comunicaciones. 2019 
Constitución Política de los Estados Unidos Mexicanos (1917). Consultado el 2 de Noviembre en: https://www.juridicas.unam.mx/legislacion/orde namiento/constitucion-política-de-los-estadosunidos-mexicanos

De Zan, J.(2004). La Ética, los derechos y la justicia. Fundación Konrad-Adenauer. ISBN 9974-7868-2-7. Recuperado de: http://www.corteidh.or.cr/tablas/23356.pdf

Diario Oficial de la Federación (27 de Marzo de 2014). Acuerdo número 01/03/14 por el que se abrogan acuerdos secretariales. Recuperada de: http://dof.gob.mx/nota_detalle.php?codigo $=533$ 8451 \&fecha $=27 / 03 / 2014$

Diccionario de la Real Academia Española (DRAE, 2017). Diccionario de la Lengua Española. Recuperado de: http://dle.rae.es

Facultad Latinoamericana de Ciencias Sociales (2008). Informe Programa Enciclomedia. México. Consultado el 10 de agosto de 2017 en https://es.scribd.com/document/347742454/Info rme-Programa-Enciclomedia

García G. M.C., Fernández M. C., Del Hoyo H.M. (2017). Ciudadanía informada, Ciudadanía participativa. La movilización de los jóvenes en el entorno digital. Prisma Social(18). ISSN-e: 1989-3469. Recuperado de: https://dialnet.unirioja.es/servlet/articulo?codig $\mathrm{o}=6220241$

García, P. J. F.,(2013). Derechos de autor en Internet. UNAM. ISBN 978-607-02-4357-8. Recuperado de: http://www.posgrado.unam.mx/publicaciones/a nt_col-posg/45_Internet.pdf

Garzón G. J. G. (2016). El derecho de autor en Internet $\mathrm{y}$ las responsabilidaddes de los proveedores de servicios de internet. Recuperado de: https://archivos.juridicas.unam.mx/www/bjv/lib ros/9/4065/14.pdf

Gobierno Federal de los Estados Unidos (s.f.) stopbullyng.gov. Qué es el ciberacoso. Consultado el 6 de septiembre en: https://espanol.stopbullying.gov/acoso-porinternet/qu\%C3\%A9-

es/ur6/\%C3\%ADndice.html
Gravante T., Sierra, C. F., Leetoy S. (2018). Ciudadanía Digital y democracia participativa. ISBN: $\quad$ 978-84-17600-04-4. Editorial Comunicación Social Ediciones y Publicaciones.

Instituto Mexicano para la competitividad A.C. (IMCO, s.f.). Nuevas tendencias de protección en materia de propiedad intelectual: retos y oportunidades para México. Recuperado de: https://imco.org.mx/wpcontent/uploads/2013/06/Documentocompleto.pdf

Internet Reputation(s.f.). Myex.com. Consultado el 15 de Noviembre en:

https://www.internetreputation.com/blog/myexremoved/

Jiménez, G. (19 de agosto de 2018). Detectan 'Pack', distribución de fotos eróticas, entre alumnos de primaria. Excelsior. https://www.excelsior.com.mx/comunidad/dete ctan-pack-distribucion-de-fotos-eroticas-entrealumnos-de-primaria/1259584

José R. Agustina (2010). ¿Menores infractores o víctimas de pornografía infantil?. Revista Electrónica de Ciencia Penal y Criminología. RECPC 12-11(2010). ISSN 1695-0194. http://criminet.ugr.es/recpc/12/recpc12-11.pdf

Kaspersky,( s.f.). ¿Qué es un keylogger? Consultado el 15 de Noviembre en:

https://latam.kaspersky.com/resourcecenter/definitions/keylogger

Lider Noticias(20 de octubre de 2017). Aquí la diferencia entre \#CIBERBULLYING Y \#CIBERACOSO. Consultado el 25 de octubre en: https://lidernoticias.com.mx/aqui-ladiferencia-ciberbullying-ciberacoso/

Lizcano, F.F. (2012) . Conceptos de ciudadano, ciudadanía y civismo. Polis Revista Latinoamericana, 32. Recuperado de: URL : http://journals.openedition.org/polis/6581

Lugo, M., \& Ithurburu, V. (2019). Políticas digitales en América Latina. Tecnologías para fortalecer la educación de calidad. Revista Iberoamericana De Educación, 79(1), 11-31. https://doi.org/https://doi.org/10.35362/rie7913 398 
Mendo, E.A. (2016). Delitos de descubrimiento y revelación de secretos: acerca de su aplicación al sexting entre adultos. Revista Electrónica de Ciencia Penal y Criminología. RECPC 1816(2016). ISSN 1695-0194. http://criminet.ugr.es/recpc/18/recpc18-16.pdf

Mesa M.(2019a). La educación para la ciudadanía global: Una apuesta por la democracia. Revista Internacional de Educación para la Justicia Social, 8(1), 15-26. https://doi.org/10.15366/riejs2019.8.1.001

Mesa M.(2019b). La Educación para la Ciudadanía Global y los Objetivos de Desarrollo Sostenible: Una Agenda para la Transformación Social. Revista Internacional de Educación para la Justicia Social, 8(1), 7-11. Recuperado de https://revistas.uam.es/riejs/article/view/10977

Olvera R. A.J. (2008). Ciudadanía y Democracia. Instituto Federal Electoral. ISBN: 970-695-111-3. Recuperado de: https://portalanterior.ine.mx/archivos3/portal/hi storico/recursos/IFE-

v2/DECEYEC/EducacionCivica/CuadernosDiv ulgacion/CuadernosDivulgacionpdfs/CUAD_27.pdf

ONG Internacional Bullying sin fronteras (11 de Noviembre de 2018). Bullying. MÉXICO. Estadísticas 2017/2018. Consultado el 15 de noviembre en: https://bullyingsinfronteras.blogspot.com/2017/ 03/bullying-mexico-estadisticas-2017.html

Organización Mundial de la Propiedad Intelectual (OMPI, 2016). Principios básicos del derecho de autor y los derechos conexos. ISBN: 978-92-805-2801-5. Recuperado de: https://www.wipo.int/edocs/pubdocs/es/wipo_p ub_909_2016.pdf

Orozco, H.J.J. y Silva, A.J.C. (2002). Los Derechos Humanos de los Mexicanos. Comisión Nacional de los Derechos Humanos. ISBN: 970644-240-5, 3ra. Edición

Pandasecurity (7 deJulio de 2017). Chrysaor: el 'spyware' más peligroso afecta también a Android. Consultado el 15 de Noviembre en: https://www.pandasecurity.com/spain/mediacen ter/seguridad/chrysaor-spyware-android/

Peña N. E. (2013). Plan Nacional de Desarrollo (2013-2018). http://pnd.gob.mx/
San-José,P.P., Flores,F.J., De la Fuente, R.S., Álvarez, A. E., García, P. L., y Gutiérrrez, B. C., (2011). Guía sobre adolescencia y sexting: qué es y cómo prevenirlo. Inteco. https://es.calameo.com/read/0032315543b9a2e $6 \mathrm{~d} 98 \mathrm{e} 5$

Rodrigo-Cano D., Picó M. J. \& Dimuro G. (2019). Los objetivos de desarrollo sostenible como marco para la acción y la intervención social y ambiental. Retos, 9, (17). Recuperada de:

https://retos.ups.edu.ec/index.php/retos/article/v iew/17.2019.02

Secretaría de Educación Pública (2008). Habilidades Digitales para todos. Consultado el 5 de agosto de 2017 en: http://ciyt.uaz.edu.mx/documents/11430/22455 3/Habilidades+Digitales+para+Todos

Secretaría de Educación Pública (2011). Acuerdo número 592 por el que se establece la articulación de la Educación Básica. México. Edición electrónica 2011. Consultado el 30 de julio de 2014 en: http://basica.sep.gob.mx/seb2010/pdf/destacado /Acuerdo_592.pdf

Universia(2012). ¿Cuál es la diferencia entre un Smartphone y los demás celulares? Argentina. http://noticias.universia.com.ar/enportada/noticia/2012/04/26/925721/cual-esdiferencia-smartphone-demas-celulares.html

UNOTV(2017). Ciberbullying y ciberacoso no son lo mismo... Ve diferencia. Consultado el 8 de Noviembre en: https://www.unotv.com/noticias/portal/nacional /detalle/ciberbullying-y-ciberacoso-son-lomismo-021928/ 